\title{
Primary Hyperparathyroidism: Comparing Cardiovascular Morbidity and Mortality in Patients Treated With Parathyroidectomy Versus Conservative Management
}

\author{
Melanie Nana $^{\mathrm{a}, \mathrm{c}, \mathrm{d}}$, Holly Morgan ${ }^{\mathrm{b}, \mathrm{c}}$, Natasha Shrikrishnapalasuriyar ${ }^{\mathrm{a}}$, Atul Kalhan ${ }^{\mathrm{a}}$
}

\begin{abstract}
Background: There is emerging evidence suggestive of endothelial and cardiovascular dysfunction in patients with mild or asymptomatic primary hyperparathyroidism (PHPT) although there is a lack of clear consensus regarding potential cardiovascular benefits post elective parathyroidectomy.
\end{abstract}

Methods: We carried out a retrospective observational study on patients with a biochemically confirmed diagnosis of PHPT who were under follow-up at our district general hospital between 1995 and 2016. The primary objective of the study was to compare all-cause mortality in patients who underwent elective parathyroidectomy versus the patients who were managed conservatively. The secondary objective of our study was to compare the rate of development of atherosclerotic cardiovascular disease (ASCVD) in the two groups.

Results: Our results showed no statistically significant difference in all-cause mortality rate in the patients managed conservatively as compared to the surgically treated group. However, the rate of ASCVD events, including coronary artery disease and hypertension, were lower in the latter group.

Conclusions: The adverse impact of PHPT on the cardiovascular system remains underrecognized with most of the evidence being derived from observational studies supporting a correlation between parathyroid hormone (PTH) levels and ASCVD events. All patients with PHPT should undergo clinical evaluation for ASCVD risks during initial workup as well as during follow-up visits. As elective parathyroidectomy is a relatively safe procedure and ASCVD risk is known to increase with age, there is a rationale to consider surgery for the majority of asymptomatic PHPT patients aged $<60$ years.

Keywords: Primary hyperparathyroidism; Atherosclerotic cardiovas-

Manuscript submitted June 17, 2019, accepted July 2, 2019

${ }^{a}$ Department of Diabetes and Endocrinology, Royal Glamorgan Hospital, Llantrisant, UK

bDepartment of Cardiology, Royal Glamorgan Hospital, Llantrisant, UK

${ }^{\mathrm{c}}$ These two authors contributed equally.

${ }^{\mathrm{d} C}$ Corresponding Author: Melanie Nana, Department of Diabetes and Endocri-

nology, Royal Glamorgan Hospital, Llantrisant, UK.

Email: trainingthetrainees@gmail.com

doi: https://doi.org/10.14740/jem573 cular disease; Coronary artery disease; Parathyroid hormone; Elective parathyroidectomy

\section{Introduction}

Primary hyperparathyroidism (PHPT) is the third most common endocrinological disorder with an estimated prevalence of $0.1-0.7 \%$ in adult population [1]. It has female preponderance $(3-4: 1)$ with a higher incidence rate at $58-146$ per 100,000 person-years in women as compared to $23-80$ per 100,000 person-years for men [2]. The majority of the patients diagnosed with PHPT are relatively asymptomatic and have mild disease [3]. In $85 \%$ of the patients, excess parathyroid hormone (PTH) secretion is secondary to a solitary parathyroid adenoma with diffuse hyperplasia of the gland accounting for the remaining $15 \%$ of the cases [4].

Elective parathyroidectomy after localisation studies (ultrasound neck/technetium-sestamibi scintigraphy, single photon emission computed tomography study) remains the definitive management for this chronic condition. The consensus guidelines for management of PHPT lays emphasis on age $(<$ 50 years), presence of end organ damage (nephrocalcinosis or nephrolithiasis, osteoporosis and or vertebral fractures) and biochemical cut off values (serum $\mathrm{Ca}>2.85 \mathrm{mmol} / \mathrm{L}$, creatinine clearance $<60 \mathrm{~mL} / \mathrm{min}, 24-\mathrm{h}$ urinary calcium $>400 \mathrm{mg} /$ day) for consideration for surgery (Supplementary figure 1, www. jofem.org) [5]. There are observational reports suggestive of endothelial and cardiovascular dysfunction in patients with mild or asymptomatic PHPT although there is a lack of conclusive evidence regarding potential cardiovascular benefits with elective parathyroidectomy [6].

PTH and calcium play a key role in maintaining cardiovascular homeostasis with both an indirect and direct effect on cardiac conduction and endothelial function [7]. PTH binds to the G-protein-coupled receptor on cardiac myocytes which leads to intracellular calcium influx and activation of protein kinase $\mathrm{c}$ (PKC) pathway [8]. PKC activation is associated with cellular proliferation and induction of myocardial hypertrophy. Epidemiological and observational studies also support an increased prevalence of hypertension, left ventricular hypertrophy (LVH), diastolic dysfunction, coronary artery disease (CAD) and aortic calcification in patients with PHPT [4, 8-10]. 


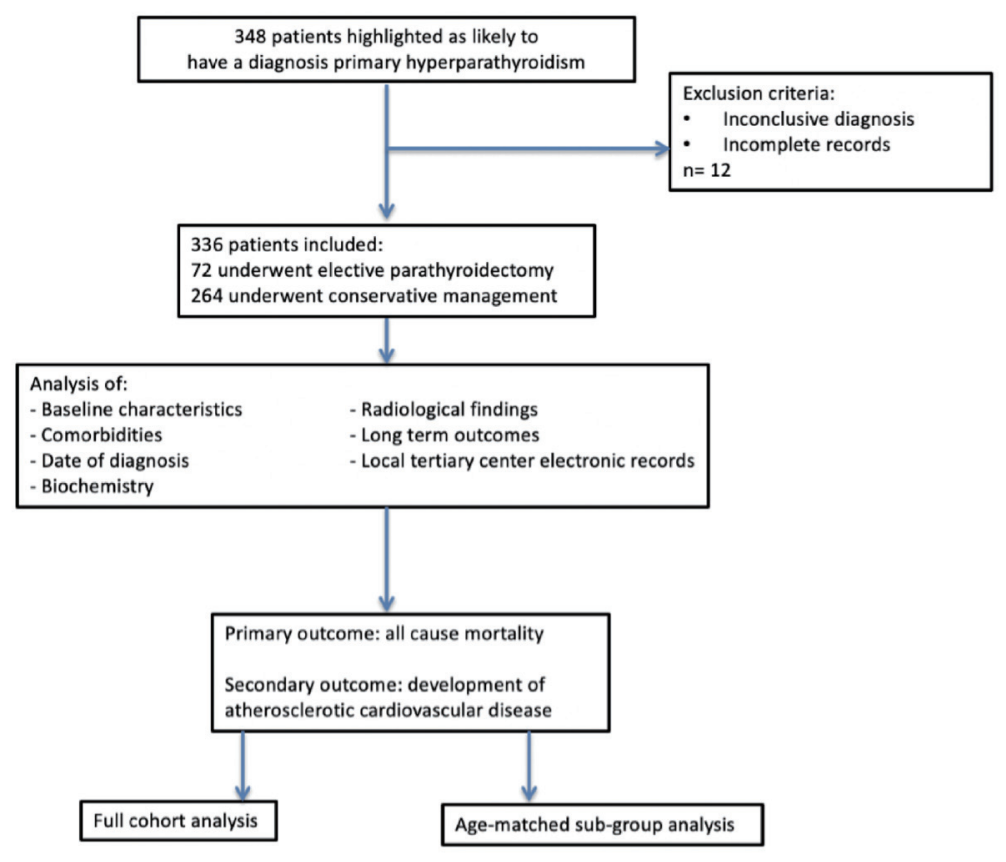

Figure 1. Methodology.

Severe PHPT has been linked with increased cardiovascular disease (CVD) mortality [11]. Recent Canadian and international consensus suggests a clinical evaluation for CVD risk assessment for perioperative risk assessment although experts do not recommend elective parathyroidectomy as a strategy to mitigate future risk of developing CVD events [11].

Keeping this background in mind, we carried out a retrospective observational study in patients with established PHPT comparing all-cause mortality and cardiovascular morbidity in patients who had undergone definitive management (elective parathyroidectomy) versus those managed conservatively. We aimed to study and analyse the baseline characteristics, allcause mortality as well as long-term atherosclerotic cardiovascular disease (ASCVD) outcomes in patients with established PHPT who were treated surgically (elective parathyroidectomy) as compared to the patients who were managed conservatively.

\section{Materials and Methods}

We carried out a retrospective observational study on patients with a biochemically confirmed diagnosis of PHPT $(n=348)$ who were under follow-up at our district general hospital from 1995 to 2016. Patients with incomplete records or who were later identified to have an alternative diagnosis were excluded from the study $(\mathrm{n}=12)$ (Fig. 1).

Case note letters and the electronic patient record system were used to establish the baseline characteristics (age and sex), comorbidities, date of diagnosis, biochemical results (bone profile, PTH level, 25-OH vitamin D level and renal function) and information regarding long-term outcomes and morbidity of these patients, including brain and vascular imaging and coronary angiography. In addition, electronic records in the local tertiary center were reviewed to ensure that all cardiovascular outcomes were identified. This study was discussed with the local ethics committee who advised that no ethical approval was required as the study was a retrospective observational study with a review of case notes and clinical information available for patients being followed up by the local health board. Patients were not subjected to any therapeutic intervention and the study did not affect their usual care. All data remained anonymous. Therefore, consent from individual patients was not required. Institutional review board approval was not required.

Patients were categorised into two groups. Group A included those patients who had undergone elective parathyroidectomy $(\mathrm{n}=72)$ and group B included those who had been managed conservatively $(n=264)$.

The primary outcome of this observational study was the comparison of all-cause mortality in patients who underwent elective parathyroidectomy versus the patients managed conservatively. The secondary outcome of the study was comparison in rate of development of ASCVD (fatal and non-fatal myocardial infarction, stable and unstable angina, fatal and non-fatal stroke, transient ischemic episodes and peripheral vascular disease) events between the two groups [12].

A further subgroup analysis was also carried out on agematched patients between the two groups (Fig. 1). This was done to neutralise any potential bias in baseline ASCVD risk due to difference in ages between the two broader groups. Seventy-two age-matched patients were randomly selected by an independent observer from the conservative management group. All-cause mortality as well as rate of ASCVD development for this subgroup of patients was compared with the patients who had undergone elective parathyroidectomy.

All statistical analysis was performed using the Statistical Package for the Social Sciences (SPSS) for Windows. The un- 
Table 1. Demographics and Baseline Biochemical Parameters of the Two Groups

\begin{tabular}{llll} 
& Conservative & Surgical & P value \\
\hline Number of patients & 264 & 72 & - \\
Male/female & $59: 277$ & $11: 61$ & - \\
Mean age in years (range) & $68.7(26-90)$ & $56.8(33-84)$ & $0.001 *$ \\
Mean S.Ca at diagnosis $(\mathrm{mmol} / \mathrm{L})$ & 2.70 & 2.72 & 0.498 \\
Mean PTH at diagnosis $(\mathrm{pg} / \mathrm{mL})$ & 11.4 & 16.5 & $0.034^{*}$ \\
\hline
\end{tabular}

Statistical tests: Mann-Whitney, unpaired $t$-test. *Denotes significance $(\mathrm{P}<0.05)$. S.Ca: serum corrected calcium; PTH: parathyroid hormone.

paired $t$-test was used for parametric data; Mann-Whitney, Chisquared and Fisher's exact tests were used for nonparametric data. The multivariate relationship between variables was studied using logistic regression analysis. Statistical significance was considered to be at the standard $\mathrm{P}$-value of $<0.05$.

\section{Results}

A total of 336 patients $(n=336)$ with confirmed PHPT were identified from retrospective analysis of case notes and electronic database (clinical portal). Out of these 336 patients, 72 patients $(n=72)$ underwent elective parathyroidectomy while $264(n=264)$ patients were managed conservatively. The decision for elective parathyroidectomy was broadly based on consensus criteria for management of PHPT (Supplementary figure 1, www.jofem.org) along with due consideration to preference of the patient and presence/absence of comorbidities [5].

\section{Baseline characteristics}

The mean age of the patients at diagnosis of hyperparathyroidism was 68.7 years in the conservative group (range: 26 - 90), and 56.8 years in the surgical cohort (range: $33-84$ ). The difference in age between the two groups was statistically significant, $\mathrm{P}$-value $<0.001$ (unpaired $t$-test). Out of the 336 patients with confirmed PHPT, there were 59 male $(\mathrm{M})$ and 277 female (F) patients; with $\mathrm{M} / \mathrm{F}$ ratio of 1:4.6. There was no significant difference in $\mathrm{M} / \mathrm{F}$ ratio in the two groups (elective parathyroidectomy group: $\mathrm{M}, \mathrm{n}=11$ and $\mathrm{F}, \mathrm{n}=61 ; \mathrm{M} / \mathrm{F}$ ratio of 1:5.7; conservative management group: $\mathrm{M}, \mathrm{n}=48$ and $\mathrm{F}$, $\mathrm{n}=188 ; \mathrm{M} / \mathrm{F}$ ratio of $1: 4.5)$. Mean duration of follow-up for the conservative group was 7.25 years, range 6 months - 23 years, and 2.42 years for the surgical group, range 4 months 13 years. This difference was statistically significant (P-value $<0.001$, Mann-Whitney test).

We compared the serum corrected calcium (S.Ca) levels at initial presentation to the endocrine clinic in both the groups. The patients who underwent elective parathyroidectomy had a mean corrected S.Ca of $2.72 \mathrm{mmol} / \mathrm{L}$ as compared to $\mathrm{S} . \mathrm{Ca}$ of $2.70 \mathrm{mmol} / \mathrm{L}$ in the patients managed conservatively. The difference in S.Ca levels between the two groups of patients was not statistically significant $(\mathrm{P}=0.494$ (unpaired $t$-test)). Mean PTH levels at diagnosis were $11.4 \mathrm{pg} / \mathrm{mL}$ (range: 3.0 104.4 ) in the conservative management group and $16.5 \mathrm{pg} / \mathrm{mL}$ (range: 3.49 - 89) in the patients managed with elective par- athyroidectomy. The PTH levels were significantly higher $(\mathrm{P}=$ 0.034; confidence interval (CI): -7.2 to -0.28 ) in patients who were treated with elective parathyroidectomy as compared to the group of patients who were managed on conservative lines (Table 1).

\section{Primary outcome}

The primary outcome of this observational study was to measure and compare all-cause mortality in the two groups. Sixtytwo out of 264 patients $(23.4 \%)$ in the conservative group and 10 out of the 72 patients $(13.8 \%)$ in the surgical group died during the two decades follow-up period for the study (Table 2 ). Figure 2 outlines the survival estimates over time. The allcause mortality rate in the patients managed conservatively as compared to the surgically treated patients showed no significant statistical difference ( $\mathrm{P}=0.104$, Fisher's test). The mean age of death was 82.7 years in the conservative group (range: $55-97$ ) and 80.4 years in the surgically treated group (range: $63-94)$.

\section{Secondary outcomes}

Elevated blood pressure (BP) was documented in 119 patients in the conservative group (45.2\%) and 18 patients in the surgical group $(25.0 \%)$. The patients who underwent elective parathyroidectomy were statistically less likely $(\mathrm{P}=0.002$, Fisher's test) to have hypertension during follow-up visit as compared to the patients who were managed by a conservative approach.

Retrospective review of case notes confirmed development of CAD-related events (unstable angina, fatal or non-fatal myocardial infarction) in 45 patients in the conservative group $(17.1 \%)$ as compared to occurrence of such events in two of the patients in the surgical group $(2.8 \%)$ during the duration of follow-up. This difference in development of CAD events was significantly ( $P=0.001$, Fisher's test) higher in patients managed conservatively as compared to the ones who were treated by elective parathyroidectomy. In regard to cerebrovascular disease, 27 out of 264 patients $(10.2 \%)$ in the conservative group experienced an ischemic or non-ischemic stroke or transient ischemic attack (TIA), representing 10\% event rate in this group. Six out of the 72 patients (8\%) who underwent elective parathyroidectomy went on to have a stroke or a TIA during the duration of follow-up. There was no statistically significant difference in development of cerebrovascular 
Table 2. Primary and Secondary Outcomes

\begin{tabular}{llll}
\hline & Conservative & Surgical & P value \\
\hline Mortality & $62(23.4 \%)$ & $10(13.8 \%)$ & 0.104 \\
Hypertension & $119(45.2 \%)$ & $18(25 \%)$ & $0.002 *$ \\
CAD-related events & $45(17.1 \%)$ & $2(2.8 \%)$ & $0.001 *$ \\
Cerebrovascular disease & $27(10.2 \%)$ & $6(8 \%)$ & 0.824 \\
Peripheral vascular disease & $22(8 \%)$ & $6(8 \%)$ & 1.00 \\
Total ASCVD events & 213 & 32 & $0.001 *$ \\
Duration of clinic follow-up in years (range) & $7.25(0.5-23)$ & $2.42(0.3-13)$ & $0.001 *$ \\
\hline
\end{tabular}

Statistical tests: Mann-Whitney, Fisher's test. *Denotes significance $(P<0.05)$. Percentage is not stated for total ASCVD as single patient may have had multiple events. CAD: coronary artery disease; ASCVD: atherosclerotic cardiovascular disease.

events or peripheral vascular disease between the two groups. There was a higher rate of total ASCVD in the conservative group compared to the surgical group. This difference was statistically significant ( $\mathrm{P}=0.001$, Fisher's test) (Fig. 3).

Duration of endocrine clinic follow-up was longer in the conservative group ( 7.25 years versus 2.42 years, $\mathrm{P}=0.001$, Fisher's test) (Table 2).

\section{Regression analysis}

On regression analysis, the odds of having ASCVD were reduced by half in the patients who underwent elective parathyroidectomy as compared to the group of patients who were managed on conservative lines, which was independent of age (odds ratio $0.482, \mathrm{P}=0.027$ ) (Table 3 ).

\section{Subgroup analysis}

To further ensure prevalence of ASCVD was not due to difference in age, a subgroup age-matched analysis was also carried out. Seventy-two age-matched conservatively managed patients were selected for subgroup analysis, and baseline pa- rameters as well as long-term outcome of this subgroup were compared to the patients who had undergone elective parathyroidectomy.

\section{Baseline characteristics (subgroup analysis)}

The two subgroups were well matched with regards to demographics (male/female ratio and age). There was no statistically significant difference in mean S.Ca levels at the time of diagnosis between the two subgroups (2.67 and $2.73 \mathrm{mmol} / \mathrm{L}$ respectively conservative versus surgical subgroup; $\mathrm{P}=0.221$ ) (Table 4). Mean PTH was higher in patients who underwent elective parathyroidectomy as compared to the age-matched subgroup of patients who were managed conservatively (15.1 versus $10.07 \mathrm{mmol} / \mathrm{L} ; \mathrm{P}=0.018$ ). Table 4 shows the difference in demographic and baseline biochemical parameters between the two age-matched groups.

\section{Primary and secondary outcomes (subgroup analysis)}

There was no statistically significant difference in all-cause mortality between the age-matched conservative group and the

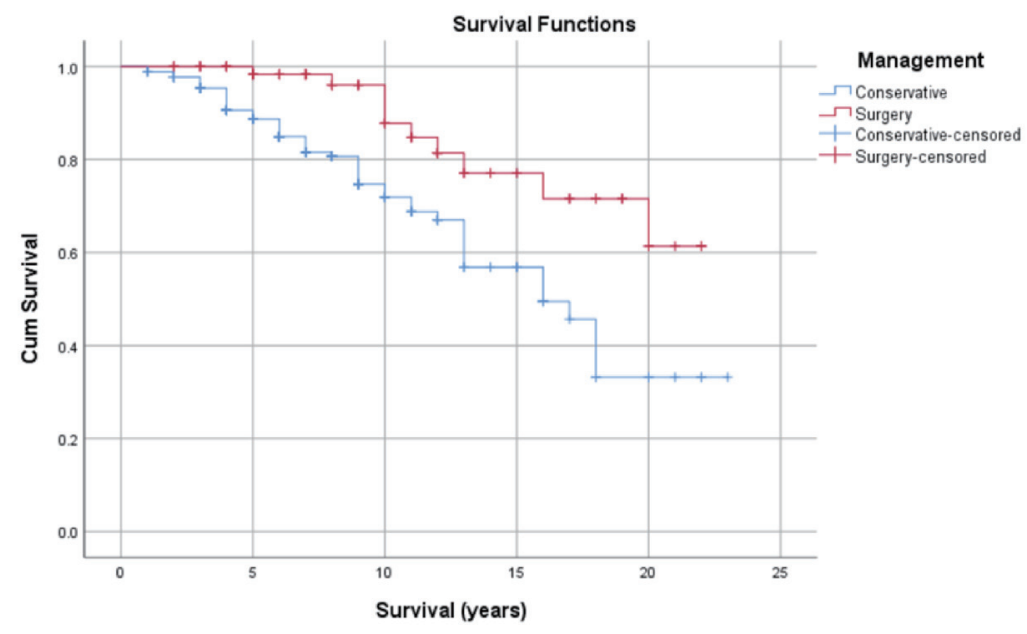

Figure 2. Kaplan-Meier survival curve showing estimated survival over time. 


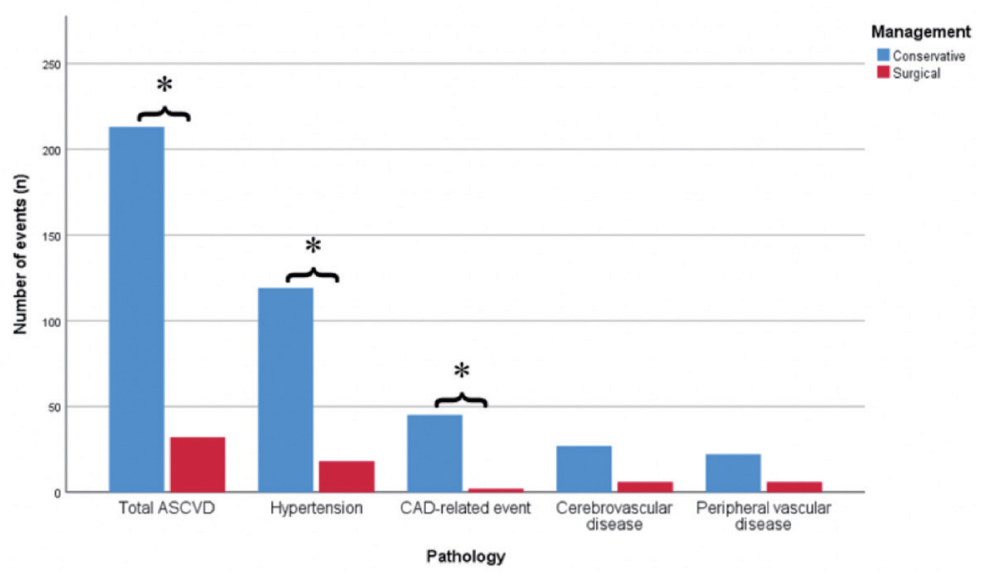

Figure 3. Bar chart showing difference in development of total ASCVD, hypertension, CAD-related events and CVD-related events between the two groups. *Denotes significance. ASCVD: atherosclerotic cardiovascular disease; CAD: coronary artery disease; CVD: cardiovascular disease.

surgical group (Table 5).

Elevated BP was documented in 31 (43\%) patients in the age-matched conservative group and 18 patients in the surgical group $(25.0 \%)$. The development of CAD-related events was recorded in $14(19 \%)$ patients in the age-matched conservative group as compared to CAD related events in two of the patients in the surgical group $(2.8 \%)$ during the duration of follow-up. This difference in development of CAD events was significantly ( $\mathrm{P}=0.002$, Fisher's test) higher in age-matched patients who were managed conservatively as compared to the patients who underwent elective parathyroidectomy. There was no statistically significant difference in development of cerebrovascular events or peripheral vascular disease.

There was a higher rate of total ASCVD events in the agematched conservative group compared to the surgical group.
This was statistically significant ( $\mathrm{P}=0.001$, Fisher's test) (Table 5 and Fig. 4).

\section{Regression analysis}

The odds of developing ASCVD were reduced by nearly three quarters in the patients who underwent elective parathyroidectomy as compared to the group of patients who were managed conservatively (odds ratio: $0.287, \mathrm{P}=0.001$ ) (Table 6).

\section{Discussion}

PHPT remains one of the commonest endocrinological dis-

Table 3. Logistic Regression Analysis

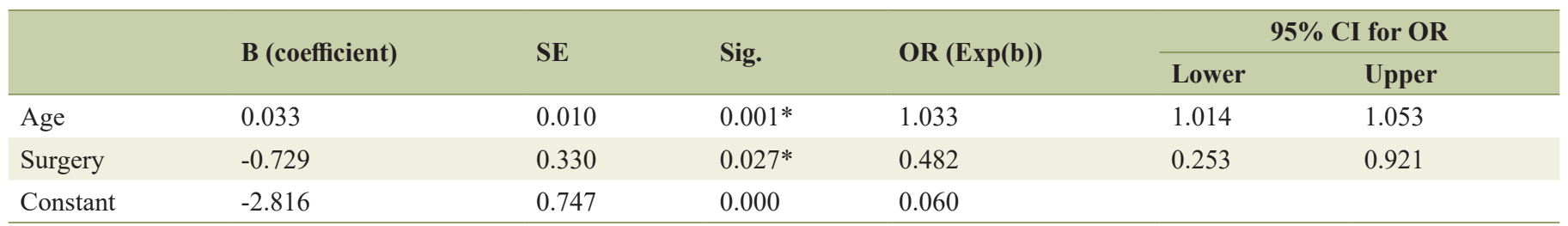

*Denotes significance $(\mathrm{P}<0.05)$. Cl: confidence interval; OR: odds ratio.

Table 4. Demographics and Baseline Biochemical Parameters of the Two Groups

\begin{tabular}{llll} 
& Conservative (age-matched subgroup) & Surgical & P value \\
\hline Number of patients & 72 & 72 & - \\
Male/female & $11: 61$ & $11: 61$ & - \\
Mean age at diagnosis & $59.8(26-87)$ & $56.8(33-84)$ & 0.139 \\
Mean age now/age at death (years) & $66.3(30-96)$ & $65.9(40-95)$ & 0.865 \\
Mean S.Ca at diagnosis (mmol/L) & 2.67 & 2.73 & 0.221 \\
Mean PTH at diagnosis (mmol/L) & 10.07 & 15.1 & $0.018^{*}$ \\
\hline
\end{tabular}

Statistical tests: Mann-Whitney, unpaired $t$-test. ${ }^{*}$ Denotes significance $(\mathrm{P}<0.05)$. S.Ca: serum corrected calcium; PTH: parathyroid hormone. 
Table 5. Primary and Secondary Outcome Data in the Two Subgroups

\begin{tabular}{llll} 
& Conservative (age-matched subgroup) & Surgical & P value \\
\hline Mortality & $6(8.3 \%)$ & $10(13.8 \%)$ & 0.427 \\
Hypertension & $31(43 \%)$ & $18(25 \%)$ & $0.022 *$ \\
CAD-related events & $14(19 \%)$ & $2(2.8 \%)$ & $0.002 *$ \\
Cerebrovascular disease & $3(4 \%)$ & $6(8 \%)$ & 0.299 \\
Peripheral vascular disease & $5(7 \%)$ & $6(8 \%)$ & 0.089 \\
Total ASCVD & 53 & 32 & $0.001 *$ \\
\hline
\end{tabular}

Statistical tests: Chi-squared, Fisher's test. *Denotes significance $(P<0.05)$. Percentage is not stated for total ASCVD as single patient may have had multiple events. CAD: coronary artery disease; ASCVD: atherosclerotic cardiovascular disease.

orders encountered in clinical practice with a majority of the patients being diagnosed incidentally at a relatively early stage of the disease $[3,13]$. Elective parathyroidectomy remains the only definitive therapeutic option for management of patients with PHPT. The consensus criteria for management of PHPT lay emphasis on well-defined criteria for surgical treatment in asymptomatic patients with PHPT (Supplementary figure 1, www.jofem.org) [5]. Elective parathyroidectomy is primarily considered based on age of the patient and evidence of end organ damage related to bones (osteoporosis) and renal systems (nephrolithiasis, hypercalciuria and declining renal function) [5]. On the other hand, although the direct and indirect impact of PHPT on cardiovascular system is supported by evidence from laboratory and observational studies, the evaluation of CVD risk remains underutilized for clinical decision making in real-life practice.

Cwm Taf University Local Health Board (LHB) covers $3 \%$ of landmass and caters to healthcare needs of $10 \%$ of the population of Wales with Royal Glamorgan Hospital (RGH) being one of the two main hospitals under the remits of this health board [14]. Our observational study had a total of 336 patients with confirmed PHPT spanning over a two-decade follow-up period at Royal Glamorgan Hospital which is responsible for healthcare needs of 145,823 adults [15].
This equates to an incidence rate 11 new patients per 100,000 population per year. There was a female preponderance of PHPT (4.6:1) in our study population which is slightly higher than previous studies [2]. The patients who underwent elective parathyroidectomy were relatively younger as compared to the group of patients who were managed conservatively (mean age at diagnosis 57.2 years in the surgical group as compared to 68.7 years in the conservative group). This is not surprising as a younger age $(<50$ years $)$ remains an important criterion for patients to be considered for elective parathyroidectomy based on consensus guidelines. In addition, there is an increased likelihood of younger patients being more likely to be deemed suitable for surgical treatment (elective parathyroidectomy).

A total of 72 out of 336 patients (21.4\%) underwent elective parathyroidectomy in our observational study. There was no statistically significant difference in the corrected S.Ca levels in both the groups $(2.72 \mathrm{mmol} / \mathrm{L}$ in surgically treated group versus $2.70 \mathrm{mmol} / \mathrm{L}$ in patients managed conservatively) of patients, which was surprising considering higher S.Ca levels $(\mathrm{S} . \mathrm{Ca}>2.85 \mathrm{mmol} / \mathrm{L})$ being one of the criteria for elective parathyroidectomy. Mean PTH levels at diagnosis were significantly higher in patients who underwent elective parathyroidectomy versus the ones who were managed

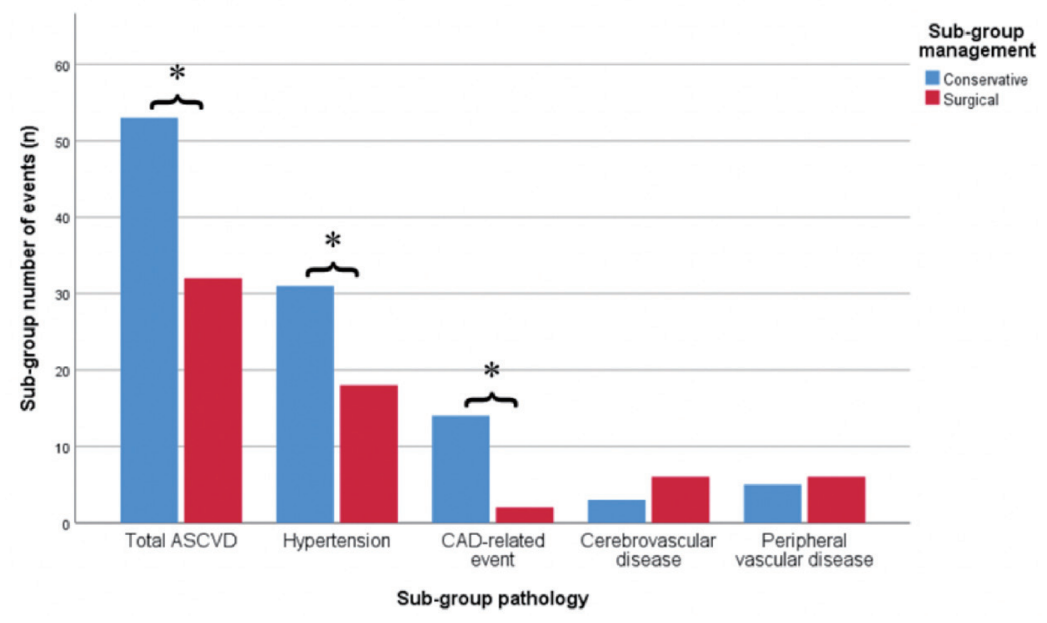

Figure 4. Bar chart showing the difference in development of total ASCVD, hypertension, CAD-related events and CVD-related events between the two age-matched subgroups. *Denotes significance $(P<0.05)$. ASCVD: atherosclerotic cardiovascular disease; CAD: coronary artery disease; CVD: cardiovascular disease. 
Table 6. Logistic Regression Analysis

\begin{tabular}{lllllll} 
& B (coefficient) & SE & Sig. & OR (Exp (b)) & \multicolumn{2}{c}{ 95\% CI for OR } \\
\cline { 5 - 7 } & -1.249 & 0.357 & $0.001^{*}$ & 0.287 & 0.142 & 0.578 \\
Surgery & -0.223 & 0.237 & 0.347 & 1.250 & & \\
\hline
\end{tabular}

$\mathrm{Cl}$ : confidence interval; OR: odds ratio.

medically (11.4 versus $16.5 \mathrm{pg} / \mathrm{mL}$; $\mathrm{P}=0.034$; $\mathrm{CI}:-7.2$ to -0.28). Similarly, on subgroup analysis, mean baseline PTH levels were higher in patients who underwent elective parathyroidectomy as compared to the age-matched patients who were managed conservatively (15.1 versus $10.07 \mathrm{mmol} / \mathrm{L}$; P $=0.018$ ). There has been emerging evidence regarding PTH levels correlating with severity of the disease, and one can argue that PTH levels need to be taken in consideration during initial decision making while evaluating patients with PHPT $[16,17]$. On the other hand, PHPT is associated with a low $25-\mathrm{OH}$ vitamin D levels which can propagate an increase in PTH levels. As a result, initial PTH results need to be interpreted cautiously specially in presence of co-existent vitamin D deficiency. The PTH and S.Ca levels do not correlate with arterial BP although age and body mass index remain strongest predictors of development of hypertension in patients with PHPT [18].

PTH acts as on G-protein-coupled receptors to activate phospholipase $\mathrm{V}$ on myocytes and protein kinase $\mathrm{A}$ on vascular endothelium [8]. The proposed mechanisms of development of cardiovascular dysfunction in PHPT include: 1) Development of hypertension: driven by alteration in vasodilatory properties of endothelium and/or hyperaldosteronism as a result of activation of renin-aldosterone-angiotensin axis (RAAS); 2) Development of LVH: driven by PTH mediated hypertrophy of cardiac myocytes, endothelial dysfunction [19]; 3) Calcification of myocardium and aorta.

Observational studies have demonstrated plausible mechanisms to support a bidirectional interplay between PTH and the renin-angiotensin-aldosterone system (RAAS). Chronic stimulation of the calcium sensing receptors has been demonstrated to increase plasma renin. Interestingly, angiotensin II may have an acute and direct effect on PTH synthesis and secretion [20]. In addition, PTH may play a direct effect on the RAAS system, through potentiation of angiotensin II induced aldosterone secretion from the zona glomerulosa cells [19-22]. It has been suggested that aldosterone may stimulate secretion of PTH by one of two mechanisms: either by virtue of a secondary hyperparathyroidism induced by a chronic aldosterone excess inducing hypercalciuria and hypocalcaemia [23], or by a more direct effect mediated via mineralocorticoid receptors in the parathyroid tissue [24].

Patients with PHPT have been observed to have an increased prevalence of hypertension and LVH [24-27]. In addition, reduction in BP and regression of $\mathrm{LVH}$ has been observed post-parathyroidectomy [28, 29]. Table 7 [25-30] summarises the studies showing association of hypertension, LVH and PHPT.

PHPT has also been associated with an increased arterial stiffness [31-34], intimal medial thickness [35], mitral valve calcification [36], aortic valve calcification [10, 37], diastolic and systolic dysfunction [37-39]. Vascular stiffness remains the most consistent cardiovascular complication associated with PHPT $[3,6]$. Table $8[10,31-35,38-41]$ summarises the studies assessing impact of primary HPT on vascular endothelium, cardiac function and valvular calcification.

The primary outcome of our study was to compare allcause mortality between the two groups of patients during the two-decade follow-up period for the study. The all-cause mortality was higher in patients who were managed conservatively $(23.4 \%)$ as compared to those who underwent elective parathyroidectomy $(13.8 \%)$ although these numbers did not reach a statistical significance. Previous studies have associated severe PHPT with an increased mortality although all-cause mortality is only a crude index of ASCVD outcome [9, 11, 42-44]. One has to be mindful of relatively older age at the time of diagnosis of the patients who were managed conservatively and in addition, the likelihood of frail health being one of the reasons for these patients to be managed conservatively. Table $9[9,11$, 42-46] summarises the studies showing an impact of PHPT on mortality.

Interestingly, we observed a significantly lower risk of development of total ASCVD events in patients treated surgically as compared to patients managed non-surgically (213 versus $32, \mathrm{P}=0.001)$.

Specifically, hypertension and CAD were lower in patients treated surgically. On the other hand, the rate of development of cerebrovascular disease in patients treated with elective parathyroidectomy was $10 \%$ as compared to $8 \%$ in patients managed conservatively, showing a lack of statistical significance $(\mathrm{P}=0.8236)$. There was also no significant difference in peripheral vascular disease events, although these numbers were small.

There is currently no robust level 1 evidence derived from randomised controlled trials supporting an increased CVD risk in patients with PHPT. The only notable systematic review (included 5,770 articles and 12 studies) and meta-analysis (12 studies) of predominantly Caucasian population with PHPT was carried out by van Ballegooijen et al in 2013 [47]. There was an increased risk for total CVD events with PHPT: pooled HR (95\% CI), 1.45 (1.24 - 1.71). The results for fatal CVD events and non-fatal CVD events were: HR 1.50 (1.18 - 1.91) and HR 1.48 (1.14 - 1.92). In addition, there is a lack of adequate literature of impact of PHPT in non-Caucasian ethnic groups.

Duration of follow-up was also reduced in the surgical group as these patients can be discharged from the clinic following surgery as opposed to patients managed conservatively 
Table 7. Literature Review of Studies Covering the Association of PHPT With Hypertension and Left Ventricular Hypertrophy

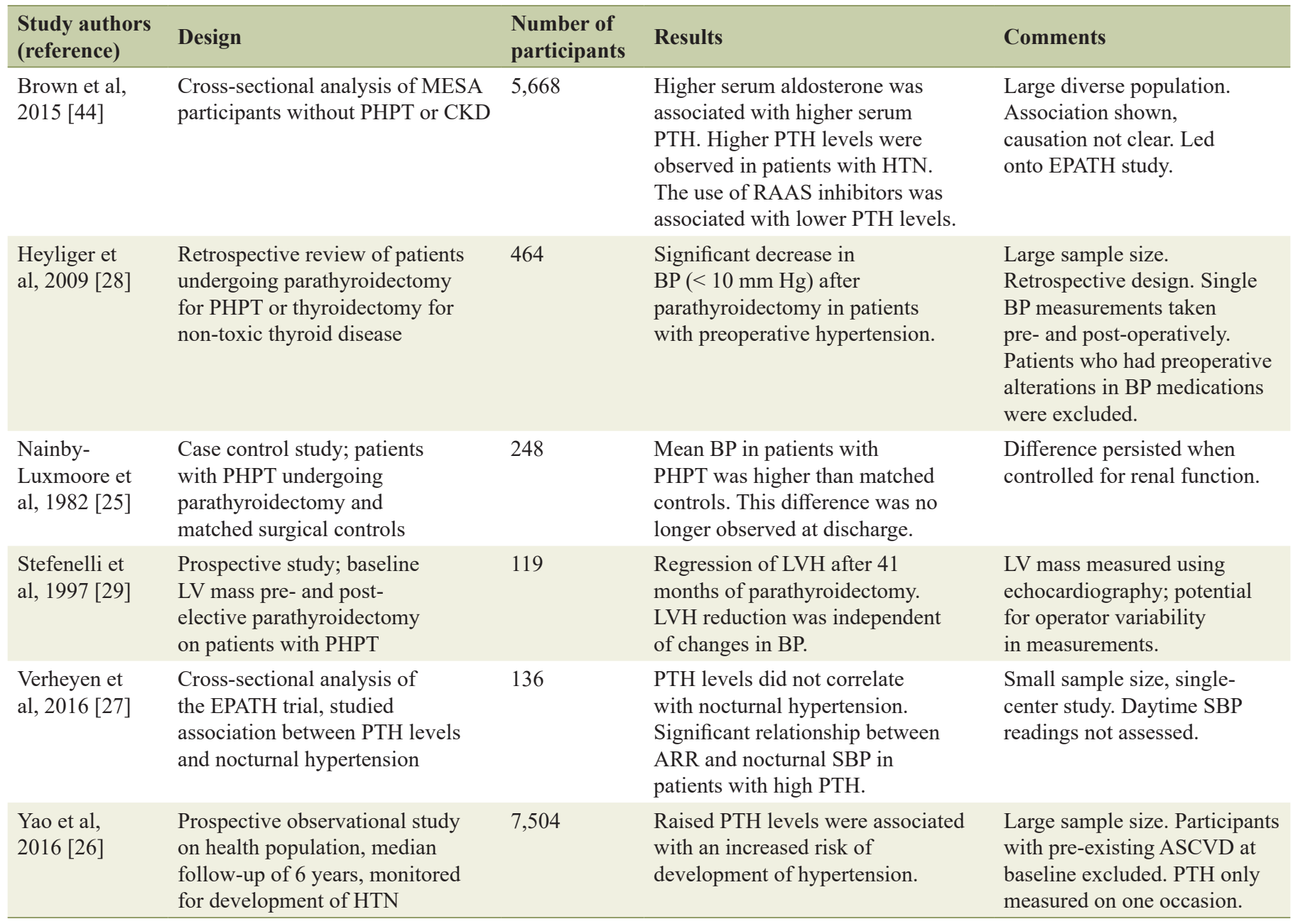

ARR: aldosterone to renin ratio; BP: blood pressure; CKD: chronic kidney disease; EPATH: "Eplerenone in Primary Hyperparathyroidism" trial; HTN: hypertension; LVH: left ventricular hypertrophy; PTH: parathyroid hormone; MESA: Multi-Ethnic Study of Atherosclerosis; PHPT: primary hyperparathyroidism; SBP: systolic blood pressure.

who tend to have prolonged monitoring. The shorter follow-up duration can potentially off-set costs associated with surgery and remains an important point to be weighed in during decision making.

We carried out a subgroup analysis of age-matched patients managed conservatively and compared the baseline biochemical parameters and ASCVD outcomes with the group of patients treated surgically. This was performed to reduce any potential bias in our initial analysis which may have been due to difference in age or comorbidities in the two groups. The age-matched patients managed conservatively were more likely to develop an ASCVD event (53 versus $32, \mathrm{P}=0.001$ ) as compared to the patients who underwent surgery. Again, this difference was accounted for by the increased hypertension and CAD-related events.

There was no statistically significant difference in development of cerebrovascular events, peripheral vascular disease or all-cause mortality between the two age-matched subgroups.

Again, the duration of follow-up for the group of patients who underwent elective parathyroidectomy was significantly shorter than the patients managed conservatively.

\section{Strengths}

Our observational study included 336 patients who were confirmed to have diagnosis of PHPT over the duration of over two decades (1995 - 2016). The case records and electronic database was evaluated in a meticulous manner. The all-cause mortality and ASCVD events were recorded manually by two independent observers.

\section{Limitations}

This is a retrospective observational study. The impact of confounding factors and age at the time of initial presentations cannot be negated. It is plausible that patients who were man- 
Table 8. Literature Review of Studies Covering Impact of PHPT on Vascular Endothelium, Cardiac Function and Valvular Calcification

\begin{tabular}{llll}
\hline $\begin{array}{l}\text { Study authors } \\
\text { (reference) }\end{array}$ & Design & $\begin{array}{l}\text { Number of } \\
\text { participants }\end{array}$ & Results \\
\hline $\begin{array}{l}\text { Bansal et al, } \\
2014[39]\end{array}$ & $\begin{array}{l}\text { Cross-sectional analysis of } \\
\text { participants of MESA. Healthy } \\
\text { cohort without ASCVD. }\end{array}$ & 6,459 & $\begin{array}{l}\text { Higher PTH associated with higher } \\
\text { levels of incident HF (hazard ratio: }\end{array}$ \\
& & & $\begin{array}{l}\text { 1.96). Higher PTH associated with } \\
\text { higher LVM (11g mean difference). }\end{array}$
\end{tabular}

$\begin{array}{ll}\text { Dalberg et al, } & \begin{array}{l}\text { Prospective case control } \\ \text { study; patients with PHPT } \\ \text { undergoing parathyroidectomy } \\ \text { and matched controls } \\ \text { undergoing thyroidectomy. }\end{array} \\ \text { Iwata et al, } & \begin{array}{l}\text { Case-control study; patients } \\ \text { with PHPT and matched } \\ \text { controls (further analysis } \\ \text { of Walker 2009 cohort). }\end{array}\end{array}$

67

diastolic dysfunction in PHPT patients when compared to controls. Reduced cardiac calcifications post parathyroidectomy.

$100 \quad$ AVCA positively associated with PTH level; no difference in peak transaortic pressure gradient.

90 PWV significantly higher in patients with PHPT and HTN compared with those with essential HTN. Surgery significantly decreased systolic BP and PWV.

\begin{tabular}{|c|c|c|c|}
\hline $\begin{array}{l}\text { Rosa et al, } \\
2011 \text { [31] }\end{array}$ & $\begin{array}{l}\text { Case-control study; } 28 \text { patients } \\
\text { with PHPT and hypertension, } \\
16 \text { with PHPT without HTN, } \\
28 \text { essential HTN patients, } \\
18 \text { healthy controls. }\end{array}$ & 90 & $\begin{array}{l}\text { PWV significantly higher in patients } \\
\text { with PHPT and HTN compared } \\
\text { with those with essential HTN. } \\
\text { Surgery significantly decreased } \\
\text { systolic BP and PWV. }\end{array}$ \\
\hline $\begin{array}{l}\text { Rubin et al, } \\
2005 \text { [32] }\end{array}$ & $\begin{array}{l}\text { Case-control study; patients } \\
\text { with mild PHPT and } \\
\text { matched healthy controls. }\end{array}$ & 173 & $\begin{array}{l}\text { PHPT was an independent predictor } \\
\text { of increased arterial stiffness. PTH } \\
\text { levels directly correlated with arterial } \\
\text { stiffness (measured by AIx) }\end{array}$ \\
\hline $\begin{array}{l}\text { Schillaci et } \\
\text { al, } 2011 \text { [34] }\end{array}$ & $\begin{array}{l}\text { Case-control study; patients } \\
\text { with mild PHPT and } \\
\text { matched healthy controls. }\end{array}$ & 72 & $\begin{array}{l}\text { Aortic PWV was significantly } \\
\text { higher among PHPT patients. Aortic } \\
\text { PWV decreased after surgery. } \\
\text { Association remained significant } \\
\text { when controlled for BP. }\end{array}$ \\
\hline $\begin{array}{l}\text { Smith et al, } \\
2000 \text { [33] }\end{array}$ & $\begin{array}{l}\text { Case-control study; patients } \\
\text { with mild PHPT and } \\
\text { matched healthy controls. }\end{array}$ & 42 & $\begin{array}{l}\text { PWA showed augmentation in } \\
\text { PHPT group significantly higher } \\
\text { than controls. Central aortic } \\
\text { systolic pressure also elevated. }\end{array}$ \\
\hline $\begin{array}{l}\text { Vestergaard et } \\
\text { al, } 2003 \text { [41] }\end{array}$ & $\begin{array}{l}\text { Case-control study, patients } \\
\text { with PHPT undergoing } \\
\text { parathyroidectomy compared } \\
\text { to matched controls. }\end{array}$ & 2,695 & $\begin{array}{l}\text { Increased incidence of acute MI in } \\
\text { PHPT patients up to } 10 \text { years prior } \\
\text { and } 1 \text { year post surgery. Increased } \\
\text { risk of HTN and HF, which did not } \\
\text { resolve by } 1 \text { year post surgery. }\end{array}$ \\
\hline $\begin{array}{l}\text { Walker et al, } \\
2009 \text { [35] }\end{array}$ & $\begin{array}{l}\text { Case-control study; patients } \\
\text { with PHPT and matched } \\
\text { healthy controls. }\end{array}$ & 1,040 & $\begin{array}{l}\text { IMT higher in PHPT patients. Odds of } \\
\text { abnormal carotid stiffness increased } \\
\text { for every } 10 \mathrm{pg} / \mathrm{mL} \text { increase in PTH. }\end{array}$ \\
\hline $\begin{array}{l}\text { Wannamethee } \\
\text { et al, } 2014 \\
{[38]}\end{array}$ & $\begin{array}{l}\text { Prospective observational } \\
\text { study of healthy cohort } \\
\text { (British Regional Heart } \\
\text { Study); 13-year follow-up. }\end{array}$ & 3,731 & $\begin{array}{l}\text { Raised PTH at baseline was associated } \\
\text { with increased CV risk factors. Higher } \\
\text { risk of incident HF with elevated PTH } \\
\text { levels (hazard ratio: 1.66) independent } \\
\text { of HTN, renal dysfunction, } \\
\text { calcium and vitamin D levels. }\end{array}$ \\
\hline
\end{tabular}

\section{Comments}

Multi-ethnic large population.

Cardiac MRI used to quantify LVM. Single baseline measurement of PTH and 25(OH)D.

Prospective design. Small sample size. Use of echocardiography associated with potential of operator bias.

Control group had more cardiovascular risk factors. Use of echocardiography associated with potential operator bias. AVCA is an indirect marker for ASCVD. Well matched baseline characteristics. Singular BP measurements (not ambulatory).

Small proportion of cases compared to controls. Surrogate marker of arterial stiffness used.

Patients with pre-existing hypertension, CV disease excluded. PWV is a surrogate marker.

PWA indirect measure of vascular stiffness (surrogate marker of clinical disease). Small sample size.

Large sample size. Historical follow-up.

Small proportion of cases compared to controls. Control group was not well matched with respect to cardiovascular risk factors.

Large sample size. Study based on older, predominately white, male population. Doctor diagnosed HF, echo not available in all patients.

25(OH)D: 25-hydroxyvitamin D; Aix: augmentation index; AVCA: aortic valve calcification area; CVD: cardiovascular disease; HF: heart failure; HTN: hypertension; IMT: intima media thickness; LVM: left ventricular mass; PHPT: primary hyperparathyroidism; PTH: parathyroid hormone; PWA: pulse wave analysis; PWV: pulse wave velocity; MRI: magnetic resonance imagining. 
Table 9. Literature Review of Studies Covering Mortality and PHPT

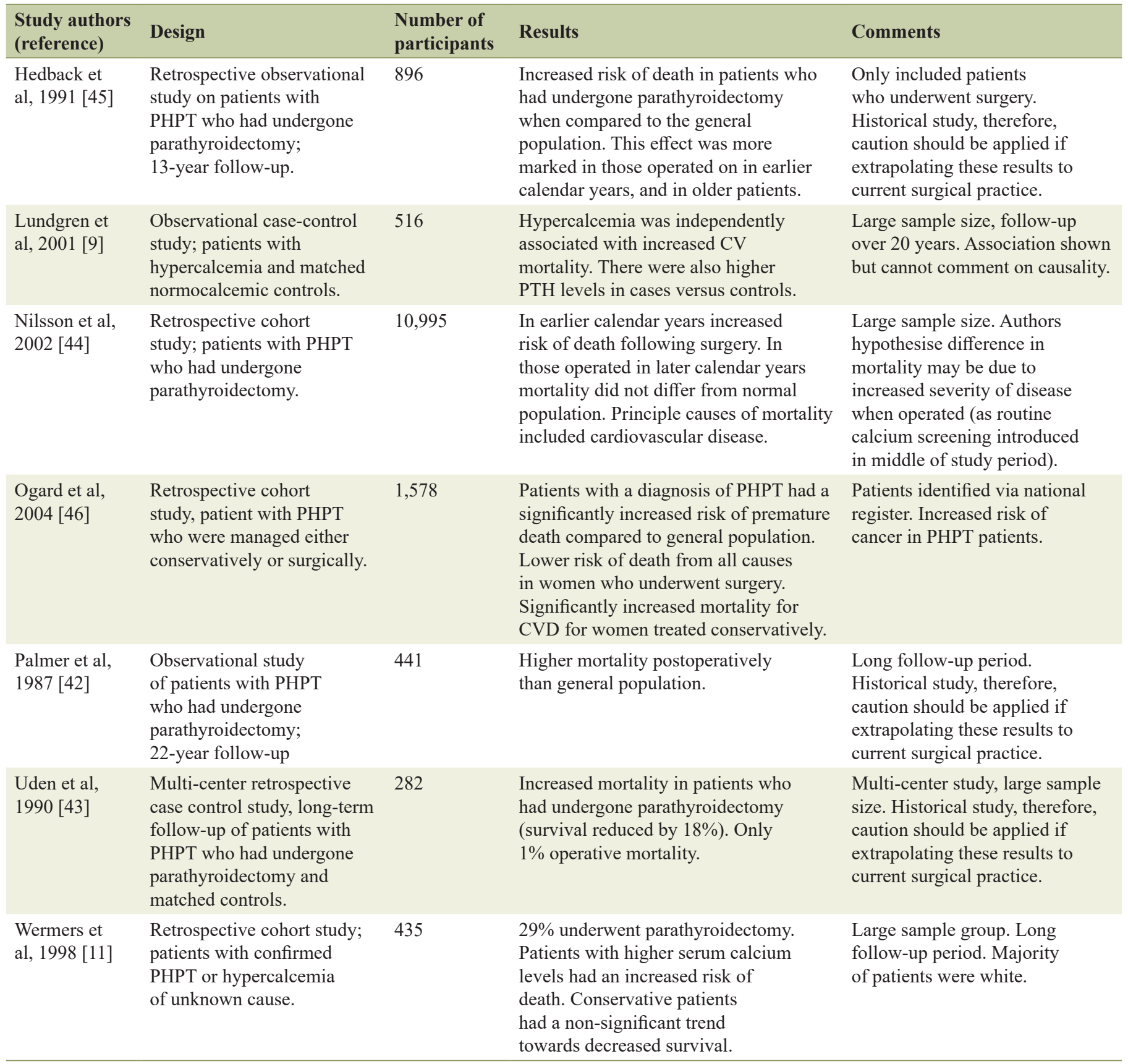

Cl: confidence interval; CVD: cardiovascular disease; PHPT: primary hyperparathyroidism; RR: relative risk.

aged conservatively were already carrying a higher cardiovascular disease burden and more likely to be risk of developing ASCVD events as compared to patients who underwent elective parathyroidectomy. Additionally, measurement of allcause and ASCVD mortality as primary outcome remains a crude index for CVD risk assessment. Measurement of carotid intimal thickness and inflammatory markers during the followup of patients who underwent elective parathyroidectomy and comparison of these parameters with patients managed medically (non-surgically) could have provided more precise infor- mation.

\section{Conclusions}

The revised consensus guidelines for management of patients with asymptomatic PHPT advocate a more proactive role on the part of the clinician to establish the presence of bone or renal disease. This approach is helpful to alleviate the increased morbidity associated with nephrocalcinosis and osteoporotic 
fractures if PHPT is left untreated. The adverse impact that PHPT poses on the cardiovascular system remains underrecognized. The physiological plausibility of increased ASCVD risk in PHPT, along with results of multiple observational studies throws important points open for debate. A thorough clinical evaluation for ASCVD risks should be part of initial workup as well as during follow-up visits of all patients presenting with PHPT. The ASCVD risk burden increases with age, and as a result there is a rationale for re-considering the age criteria for elective parathyroidectomy (perhaps to patients aged $<$ 60 years), particularly in view of improved surgical outcomes in the older patient population [48]. Alternatively, should we consider less invasive method to avoid some of these potential long-term complications by using an early trial of aldosterone antagonists in the management pathway as demonstrated in the EPATH (effect of eplerenone on PTH levels in patients with PHPT) trial results? Ultimately, there is a strong need to design prospective double-blind randomised controlled trial in patients with PHPT to provide further evidence regarding CVD risk in such patients.

\section{Acknowledgments}

None to declare.

\section{Financial Disclosure}

This research did not receive any specific grants from any funding agency in the public, commercial or not-for-profit sector.

\section{Conflict of Interest}

We have no conflict of interest to declare.

\section{Informed Consent}

Not applicable.

\section{Author Contributions}

Melanie Nana and Holly Morgan were involved in the design, data collection, analysis and write up of the work. Natasha Shrikrishnapalasuriyar was involved in the design and data collection. Atul Kalhan was involved in the design, analysis and write up of the work.

\section{References}

1. Yeh MW, Ituarte PH, Zhou HC, Nishimoto S, Liu IL, Harari $\mathrm{A}$, Haigh $\mathrm{PI}$, et al. Incidence and prevalence of primary hyperparathyroidism in a racially mixed population.
J Clin Endocrinol Metab. 2013;98(3):1122-1129.

2. $\mathrm{Yu}$ N, Donnan PT, Murphy MJ, Leese GP. Epidemiology of primary hyperparathyroidism in Tayside, Scotland, UK. Clin Endocrinol (Oxf). 2009;71(4):485-493.

3. Bandeira L, Bilezikian J. Primary Hyperparathyroidism. F1000Res. 2016;5:F1000 Faculty Rev;1.

4. Andersson P, Rydberg E, Willenheimer R. Primary hyperparathyroidism and heart disease - a review. Eur Heart J. 2004;25(20):1776-1787.

5. Bilezikian JP, Brandi ML, Eastell R, Silverberg SJ, Udelsman R, Marcocci C, Potts JT, Jr. Guidelines for the management of asymptomatic primary hyperparathyroidism: summary statement from the Fourth International Workshop. J Clin Endocrinol Metab. 2014;99(10):3561-3569.

6. Bilezikian JP, Cusano NE, Khan AA, Liu JM, Marcocci C, Bandeira F. Primary hyperparathyroidism. Nat Rev Dis Primers. 2016;2:16033.

7. Brown SJ, Ruppe MD, Tabatabai LS. The Parathyroid Gland and Heart Disease. Methodist Debakey Cardiovasc J. 2017;13(2):49-54.

8. Schluter KD, Piper HM. Cardiovascular actions of parathyroid hormone and parathyroid hormone-related peptide. Cardiovasc Res. 1998;37(1):34-41.

9. Lundgren E, Lind L, Palmer M, Jakobsson S, Ljunghall S, Rastad J. Increased cardiovascular mortality and normalized serum calcium in patients with mild hypercalcemia followed up for 25 years. Surgery. 2001;130(6):978-985.

10. Iwata S, Walker MD, Di Tullio MR, Hyodo E, Jin Z, Liu R, Sacco RL, et al. Aortic valve calcification in mild primary hyperparathyroidism. J Clin Endocrinol Metab. 2012;97(1):132-137.

11. Wermers RA, Khosla S, Atkinson EJ, Grant CS, Hodgson SF, O'Fallon WM, Melton LJ, 3rd. Survival after the diagnosis of hyperparathyroidism: a population-based study. Am J Med. 1998;104(2):115-122.

12. American Diabetes A. 8. Cardiovascular disease and risk management. Diabetes Care. 2016;39(Suppl 1):S60-71.

13. Silverberg SJ, Clarke BL, Peacock M, Bandeira F, Boutroy S, Cusano NE, Dempster D, et al. Current issues in the presentation of asymptomatic primary hyperparathyroidism: proceedings of the Fourth International Workshop. J Clin Endocrinol Metab. 2014;99(10):3580-3594.

14. PHWO. Demography overview public health wales observatory 2016. Available from: http://www.publichealthwalesobservatory.wales.nhs.uk/demography-overview.

15. Wales S. Population estimates by local health boards and age: Welsh Government; 2017. Available from: https:// statswales.gov.wales/Catalogue/Population-and-Migration/Population/Estimates/Local-Health-Boards/populationestimates-by-lhb-age.

16. Yu N, Leese GP, Donnan PT. What predicts adverse outcomes in untreated primary hyperparathyroidism? The Parathyroid Epidemiology and Audit Research Study (PEARS). Clin Endocrinol (Oxf). 2013;79(1):27-34.

17. Bjorkman MP, Sorva AJ, Tilvis RS. Elevated serum parathyroid hormone predicts impaired survival prognosis in a general aged population. Eur J Endocrinol. 2008;158(5):749-753. 
18. Lumachi F, Ermani M, Luisetto G, Nardi A, Basso SM, Camozzi V, Favia G. Relationship between serum parathyroid hormone, serum calcium and arterial blood pressure in patients with primary hyperparathyroidism: results of a multivariate analysis. Eur J Endocrinol. 2002;146(5):643-647.

19. McDow AD, Sippel RS. Should Symptoms Be Considered an Indication for Parathyroidectomy in Primary Hyperparathyroidism? Clin Med Insights Endocrinol Diabetes. 2018;11:1179551418785135.

20. Grant FD, Mandel SJ, Brown EM, Williams GH, Seely EW. Interrelationships between the renin-angiotensinaldosterone and calcium homeostatic systems. J Clin Endocrinol Metab. 1992;75(4):988-992.

21. Isales CM, Barrett PQ, Brines M, Bollag W, Rasmussen H. Parathyroid hormone modulates angiotensin II-induced aldosterone secretion from the adrenal glomerulosa cell. Endocrinology. 1991;129(1):489-495.

22. Olgaard K, Lewin E, Bro S, Daugaard H, Egfjord M, Pless V. Enhancement of the stimulatory effect of calcium on aldosterone secretion by parathyroid hormone. Miner Electrolyte Metab. 1994;20(5):309-314.

23. Brown JM, Vaidya A. Interactions between adrenal-regulatory and calcium-regulatory hormones in human health. Curr Opin Endocrinol Diabetes Obes. 2014;21(3):193201.

24. Brown J, de Boer IH, Robinson-Cohen C, Siscovick DS, Kestenbaum B, Allison M, Vaidya A. Aldosterone, parathyroid hormone, and the use of renin-angiotensin-aldosterone system inhibitors: the multi-ethnic study of atherosclerosis. J Clin Endocrinol Metab. 2015;100(2):490-499.

25. Nainby-Luxmoore JC, Langford HG, Nelson NC, Watson RL, Barnes TY. A case-comparison study of hypertension and hyperparathyroidism. J Clin Endocrinol Metab. 1982;55(2):303-306.

26. Yao L, Folsom AR, Pankow JS, Selvin E, Michos ED, Alonso A, Tang W, et al. Parathyroid hormone and the risk of incident hypertension: the Atherosclerosis Risk in Communities study. J Hypertens. 2016;34(2):196-203.

27. Verheyen N, Fahrleitner-Pammer A, Pieske B, Meinitzer A, Belyavskiy E, Wetzel J, Gaksch M, et al. Parathyroid hormone, aldosterone-to-renin ratio and fibroblast growth factor-23 as determinants of nocturnal blood pressure in primary hyperparathyroidism: the eplerenone in primary hyperparathyroidism trial. J Hypertens. 2016;34(9):17781786.

28. Heyliger A, Tangpricha V, Weber C, Sharma J. Parathyroidectomy decreases systolic and diastolic blood pressure in hypertensive patients with primary hyperparathyroidism. Surgery. 2009;146(6):1042-1047.

29. Stefenelli T, Abela C, Frank H, Koller-Strametz J, Globits $\mathrm{S}$, Bergler-Klein J, Niederle B. Cardiac abnormalities in patients with primary hyperparathyroidism: implications for follow-up. J Clin Endocrinol Metab. 1997;82(1):106112.

30. Brown JM, Williams JS, Luther JM, Garg R, Garza AE, Pojoga $\mathrm{LH}$, et al. Human interventions to characterize novel relationships between the renin-angiotensin-aldosterone system and parathyroid hormone. Hypertension.
2014;63(2):273-80.

31. Rosa J, Raska I, Jr., Wichterle D, Petrak O, Strauch B, Somloova Z, Zelinka T, et al. Pulse wave velocity in primary hyperparathyroidism and effect of surgical therapy. Hypertens Res. 2011;34(3):296-300.

32. Rubin MR, Maurer MS, McMahon DJ, Bilezikian JP, Silverberg SJ. Arterial stiffness in mild primary hyperparathyroidism. J Clin Endocrinol Metab. 2005;90(6):33263330.

33. Smith JC, Page MD, John R, Wheeler MH, Cockcroft JR, Scanlon MF, Davies JS. Augmentation of central arterial pressure in mild primary hyperparathyroidism. J Clin Endocrinol Metab. 2000;85(10):3515-3519.

34. Schillaci G, Pucci G, Pirro M, Monacelli M, Scarponi AM, Manfredelli MR, Rondelli F, et al. Large-artery stiffness: a reversible marker of cardiovascular risk in primary hyperparathyroidism. Atherosclerosis. 2011;218(1):96101.

35. Walker MD, Fleischer J, Rundek T, McMahon DJ, Homma S, Sacco R, Silverberg SJ. Carotid vascular abnormalities in primary hyperparathyroidism. J Clin Endocrinol Metab. 2009;94(10):3849-3856.

36. Walker MD, Rubin M, Silverberg SJ. Nontraditional manifestations of primary hyperparathyroidism. J Clin Densitom. 2013;16(1):40-47.

37. Pepe J, Cipriani C, Sonato C, Raimo O, Biamonte F, Minisola S. Cardiovascular manifestations of primary hyperparathyroidism: a narrative review. Eur J Endocrinol. 2017;177(6):R297-R308.

38. Wannamethee SG, Welsh P, Papacosta O, Lennon L, Whincup PH, Sattar N. Elevated parathyroid hormone, but not vitamin D deficiency, is associated with increased risk of heart failure in older men with and without cardiovascular disease. Circ Heart Fail. 2014;7(5):732-739.

39. Bansal N, Zelnick L, Robinson-Cohen C, Hoofnagle AN, Ix JH, Lima JA, Shoben AB, et al. Serum parathyroid hormone and 25-hydroxyvitamin D concentrations and risk of incident heart failure: the Multi-Ethnic Study of Atherosclerosis. J Am Heart Assoc. 2014;3(6):e001278.

40. Dalberg K, Brodin LA, Juhlin-Dannfelt A, Farnebo LO. Cardiac function in primary hyperparathyroidism before and after operation. An echocardiographic study. Eur J Surg. 1996;162(3):171-176.

41. Vestergaard P, Mollerup CL, Frokjaer VG, Christiansen P, Blichert-Toft M, Mosekilde L. Cardiovascular events before and after surgery for primary hyperparathyroidism. World J Surg. 2003;27(2):216-222.

42. Palmer M, Adami HO, Bergstrom R, Akerstrom G, Ljunghall S. Mortality after surgery for primary hyperparathyroidism: a follow-up of 441 patients operated on from 1956 to 1979 . Surgery. $1987 ; 102(1): 1-7$.

43. Uden P, Tibblin S. Mortality in patients surgically treated for primary hyperparathyroidism due to solitary adenoma. Ann Chir Gynaecol. 1990;79(3):123-128.

44. Nilsson IL, Yin L, Lundgren E, Rastad J, Ekbom A. Clinical presentation of primary hyperparathyroidism in Europe - nationwide cohort analysis on mortality from nonmalignant causes. J Bone Miner Res. 2002;17(Suppl 2):N68-74. 
45. Hedback G, Oden A, Tisell LE. The influence of surgery on the risk of death in patients with primary hyperparathyroidism. World J Surg. 1991;15(3):399-405; discussion 406-397.

46. Ogard CG, Engholm G, Almdal TP, Vestergaard H. Increased mortality in patients hospitalized with primary hyperparathyroidism during the period 1977-1993 in Denmark. World J Surg. 2004;28(1):108-111.
47. van Ballegooijen AJ, Reinders I, Visser M, Brouwer IA. Parathyroid hormone and cardiovascular disease events: A systematic review and meta-analysis of prospective studies. Am Heart J. 2013;165(5):655-664, e651-655.

48. Norenstedt S, Ekbom A, Brandt L, Zedenius J, Nilsson IL. Postoperative mortality in parathyroid surgery in Sweden during five decades: improved outcome despite older patients. Eur J Endocrinol. 2009;160(2):295-299. 